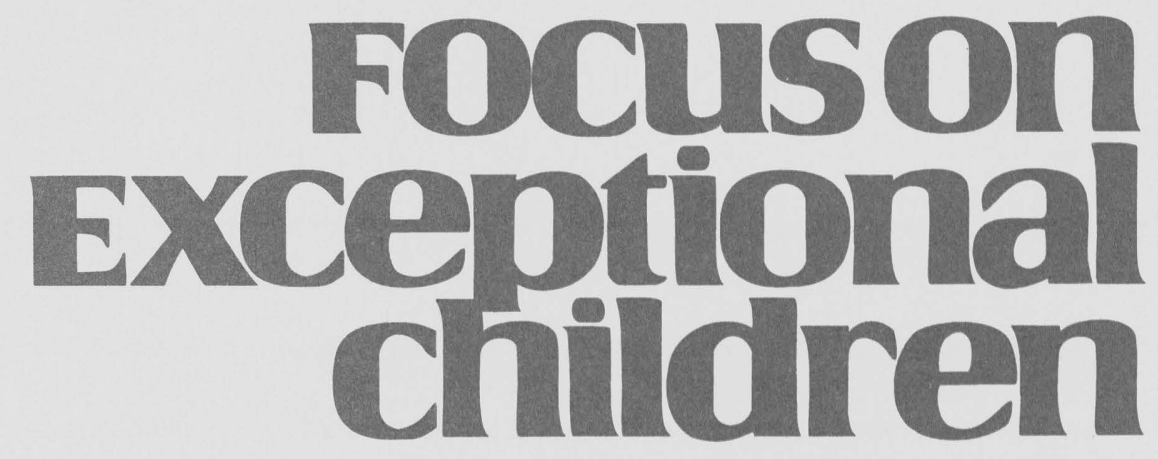

\title{
Facilitated Communication and Children with Disabilities: An Enigma in Search of a Perspective
}

\author{
Richard L. Simpson and Brenda Smith Myles
}

As defined by Crossley $(1988,1992 a)$ and Biklen $(1990,1992)$, facilitated communication is an augmentative communication method that permits individuals with severe disabilities such as autism to demonstrate unanticipated, and in some instances extraordinary, communication skills. Sustained by hand-over-hand support or other types of physical assistance from an individual without disabilities, people with disabilities who are thought to have limited communication ability purportedly are able to type thoughts and ideas, using facilitated communication, that are nothing short of remarkable. After only minimal experience with facilitated communication, individuals with severe disabilities allegedly have communicated that they have normal intelligence and adept social skills and knowledge. Other individuals reportedly have revealed that through facilitated communication, they are for the first time in their lives able to communicate.

Still, others with severe disabilities purportedly have communicated that they are trapped within a body that prohibits them from moving or communicating with others competently because of a condition known as global apraxia (Biklen \& Schubert, 1991; Calculator, 1992). Biklen (1992) proposed that individuals with global apraxia might seem to have severe language deficits and mental retardation in spite of having intact language processing abilities and normal intelligence. Thus, when afforded facilitated communication, these individuals demonstrate normal intelligence and advanced social skills, literacy, and communication abilities.

Rosemary Crossley, an Australian, is acknowledged as the developer of facilitated communication. During the 1970s she worked at the St. Nicholas Institution in Melbourne with individuals having multiple disabilities, most of whom were thought to have severe and profound retardation. At St. Nicholas, Crossley became involved with a young woman by the name of Anne McDonald, who had athetoid cerebral palsy. Anne was unable to effectively communicate, feed herself, or walk. The staff at the institution believed her to have profound retardation. Crossley, however, was convinced that Anne had more ability than she was given credit for and considered her capable of communication if given the correct assistance and opportunity.

By supporting Anne's index finger, Crossley found that Anne was able to identify many objects by pointing. Using a procedure similar to what now is known as facilitated communication, Crossley was able to assist Anne to read and write by pointing to letters

Richard Simpson is a professor and Brenda Myles is an assistant professor in the Department of Special Education at the University of Kansas. 
with facilitation. In 1979, when Anne was 18 years of age, she left the institution to live with Crossley. Later, Crossley and McDonald were instrumental in closing the St. Nicholas institution, based on claims that the staff treated residents in a neglectful and inhumane fashion (Crossley, 1992a).

In 1986 the Dignity through Education and Language Communication Centre (DEAL) opened in Victoria, Australia, to assist individuals with severe communication disorders and to evaluate and recommend augmentative communication aids. Crossley, an employee of DEAL and her colleagues found that more than $70 \%$ of those with severe communication disorders had been labeled "mentally retarded," and that $90 \%$ had difficulty using their hands. Accordingly, Crossley introduced facilitated communication to DEAL, because the clients' physical problems did not allow them to use sign language and standard augmentative communication devices readily. Facilitated communication was determined to be an effective communication option for a variety of DEAL's clients, including those thought to have mental retardation and autism (Biklen, 1990; Crossley, 1992a).

Douglas Biklen is given credit for introducing facilitated communication in the United States (Biklen, 1990, 1993). He

\section{Focuson
exceptional
childiren}

ISSN 0015-511X

FOCUS ON EXCEPTIONAL CHILDREN (USPS 203-360) is published monthly except June, July, and August as a service to teachers, special educators, curriculum specialists, administrators, and those concerned with the special education of exceptional children. This publication is annotated and indexed by the ERIC Clearinghouse on Handicapped and Gifted Children for publication in the monthly Current Index to Journals in Education (CIJE) and the quarterly index, Exceptional Children Education Resources (ECER). The full text of Focus on Exceptional Children is also available in the electronic versions of the Education Index. It is also available in microfilm from Xerox University Microfilms, Ann Arbor, MI. Subscription rates: Individual, \$30 per year; institutions, $\$ 40$ per year. Copyright (C) 1995, Love Publishing Company. All rights reserved. Reproduction in whole or part without written permission is prohibited. Printed in the United States of America. Second class postage is paid at Denver, Colorado. POSTMASTER: Send address changes to:

$$
\begin{aligned}
& \text { Love Publishing Company } \\
& \text { Executive and Editorial Office } \\
& 1777 \text { South Bellaire Street } \\
& \text { Denver, Colorado } 80222 \\
& \text { Telephone (303) } 757-2579
\end{aligned}
$$

Edward L. Meyen

University of Kansas
Glenn A. Vergason Georgia State University

Richard J. Whelan

University of Kansas Medical Center
Stanley F. Love

Publisher
Holly T. Rumpler Senior Editor witnessed a demonstration of facilitated communication at the DEAL Centre in 1988, during which individuals with severe disabilities revealed unexpected literacy and abilities. Biklen was impressed by the alleged desire of many of these students to be in normalized educational settings and to be able to use their facilitated communication academic and social skills in general education classrooms. Upon his return to the United States, Biklen introduced facilitated communication to the Syracuse, New York, public schools. Based on the remarkable success he found using facilitated communication in Syracuse, Biklen wrote an article extolling the virtues of this method (Biklen, 1990).

From that point, word of facilitated communication spread throughout the United States and beyond. Many individuals perceived it to be the breakthrough that ultimately would allow people with autism and other severe disabilities to reveal their true abilities. Remarking on the rapid dissemination of facilitated communication information, Rimland (1992) observed that "facilitated communication workshops spread throughout the country and virtually every major newspaper, news magazine and news show ran stories on facilitated communication" (p. 1). Because of its unique interactive nature and lack of scientific support, controversy also quickly became an element of facilitated communication (Calculator, 1992; Rimland, 1992a, 1993; Schopler, 1992).

Claims regarding the effectiveness and utility of facilitated communication have been nothing short of remarkable. Biklen (1992) described facilitated communication with Mark, a seriously impaired 7-year-old boy: "Without facilitation, Mark has no effective means of communicating, save to grab objects, pull people to objects or events that might be of interest to him, or throw tantrums. With facilitation, he can say what is on his mind, he can converse with other students, and he is doing school work at and above the grade level norm for his age" (p. 15). Biklen (1990) also claimed that most seriously impaired individuals with autism and other severe disabilities of various ages are literate, and that after brief training in facilitated communication, they can communicate at an advanced level on a variety of sophisticated topics such as politics, economics, science, and history.

Crossley (1992b) reported that facilitated communication allowed one youth "diagnosed as autistic, and assessed as having an IQ of 50," to transfer from a special education program to a high school, where "she is now [1990] handling the regular year 11 syllabus successfully" (p. 1). Using similar anecdotal evaluation methods, Biklen and Schubert (1991) reported positive facilitated communication intervention results with 21 students with whom they worked. They observed, however, that facilitated communication was a method that should not and could not be subjected to robust forms of scientific evaluation, arguing that objective scientific methods were ineffective in assessing the efficacy of facilitated com- 
munication because individuals with autism would resist communicating with more than one facilitator. In addition, they claimed that systematic, scientific validation attempts of facilitated communication would violate the trust bond between communicator and facilitator by suggesting that the individual with a disability was incompetent or incapable of advanced communication. Because of these factors, Crossley (1988; 1992b) and Biklen and Schubert (1991) have contended that objective, scientific validation of facilitated communication is ill-advised.

Some, of course, doubt that facilitated communication is a valid and reliable procedure (Prior \& Cummins, 1992). The Advocate, newsletter of the Autism Society of America, reported that "hard evidence for the authenticity of FC [facilitated communication] is nearly nonexistent" (1992-93, p. 19). Calculator (1992) contended that, in the absence of objective scientific evidence, facilitated communication is little more than a "ouija board phenomenon." Indeed, the scientific facilitated communication validation studies that have been conducted have concluded consistently that when facilitators lack information related to questions asked of an individual being facilitated, no evidence has been forthcoming that these individuals have been able to communicate independently (Hudson, Melita, \& Arnold, 1993; Intellectual Disability Review Panel, 1989; Mulick, Jacobson \& Kobe, 1993; Myles \& Simpson, in press; Prior \& Cummins, 1992; Rimland, 1992b, 1993; Simpson \& Myles, 1995; Szempruch \& Jacobson, 1993; Wheeler, Jacobson, Paglieri \& Schwartz, 1993).

As exemplified by Bernard Rimland's description of a facilitated communication "horror story," there have been reports of grievously harmed individuals with disabilities and their families by facilitated communication. Rimland reported that, according to the Australian newspaper The Sunday Age, a 29-year-old woman with retardation was removed from her home after communicating through facilitated communication that her family had abused her sexually. According to the article, the woman was removed from her home on two separate occasions after typing, during facilitated communication, that she wanted to leave home to escape sexual abuse. Subsequent to removal from the family from whom she had purportedly asked to escape however, the woman reportedly was distraught. To establish reliability regarding the reported abuse, the Australian government contracted two facilitators, one of whom was unfamiliar with the woman, to work with the woman. The woman's facilitated communication reports of sexual abuse came under serious question when she was unable to answer basic questions, such as her father's name and the name of the family pet. Moreover, she spelled her own name incorrectly, in spite of otherwise using sophisticated grammar and spelling.

As a means of resolving the issue of who was communicating, the Phillip Institute of Australia conducted a series of tests wherein the staff of the center she attended prepared 40 questions, to which she reportedly knew the answers. The facilitator with whom she was accustomed to working taped the questions. This facilitator assisted the woman in answering the 40 questions under four separate conditions: (a) both the woman and the facilitator were permitted to hear the questions; (b) while wearing earphones the facilitator and the woman heard the same questions; (c) while wearing earphones the facilitator and the woman heard different questions; and (d) while wearing earphones the facilitator heard only music while the woman heard the questions.

The study revealed that under condition a the woman correctly knew eight or nine of 10 items; under condition $b$ she correctly answered 4 of 10 items; under condition c the woman answered her own questions incorrectly, but answered correctly four questions that only the facilitator heard; and under condition $\mathrm{d}$ the woman answered every question incorrectly. Based on these results the investigators concluded that the woman was unable to communicate independently. Subsequent investigations revealed that the woman was unable to even recognize letters of the alphabet.

A variety of popular magazine, radio, and television shows have reported on facilitated communication. These include Prime Time (1992), The Six O'Clock News with Dan Rather (1992), Frontline (1993), and 60 Minutes (1994). Some of these programs have provide emotive "evidence" that facilitated communication allows the full potential of persons with autism to be realized, and in some instances facilitated communication was described as a "cure for autism." It is understandable that many families and professionals would perceive facilitated communication, which claims to offer astonishing improvement with only minimal investments of time and training, to be the technique offering the best hope for significant improvement for individuals with autism and other serious disabilities. Accordingly, it is appreciable that many families and professionals would request that facilitated communication become a regular component of their children's educational programs. At the same time, it is predictable that many schools, agencies, and professionals are reluctant to commit significant resources to facilitated communication without having clear evidence that it works.

Thus, parents and families who want the best and most effective opportunities for their family members with severe disabilities such as autism inevitably will come into conflict with professionals committed to using validated, best practices. These conflicts likely will continue until these parties come to agreement on the role and validity of facilitated communication as an educational tool. Thus, a number of authorities have recommended that validation of facilitated communication with individuals with disabilities must precede its widespread adoption (Rimland, 1992b; Schopler, 1992; Simpson, 1993). In this regard, Calculator (1992) noted, "In the absence of 
empirical evidence, this communication technique [facilitated communication] remains one that is characterized by its ambiguity, mystique, recurring anecdotes, and spiritual underpinnings" (p. 18)." Schopler (1992) observed, "If the rhetoric and media hype boosting 'facilitated communication' without research accountability continues, it may succeed in setting autism back 40 years" (p. 6).

In spite of suggestions that facilitated communication cannot or should not be evaluated and critically analyzed objectively (Biklen et al., 1992), we strongly contend that critical assessment and rigorous analysis of facilitated communication is a sine qua non of its being understood and accepted as a genuine educational tool. We believe this is the only means by which facilitated communication will find its legitimate way into mainstream educational settings such as public schools. Accordingly, in this article we discuss a variety of scientific, methodological, and ethical issues associated with facilitated communication, along with suggestions for better understanding of this novel method.

\section{IS FACILITATED COMMUNICATION AN EFFECTIVE COMMUNICATION TOOL?}

The salient question relative to facilitated communication is, "Does it work?" When physically assisted in communicating by a nondisabled individual, can individuals with severe disabilities such as autism communicate independently at a level that significantly transcends their estimated cognitive, language, and social abilities?

Table 1 confirms clearly that when facilitated communication is subjected to objective, scientific validation, individuals being facilitated are able to respond correctly only to the extent that their facilitators have the information needed to answer questions and otherwise communicate, and that extraordinary communication fails to occur. In this regard, we have analyzed in Table 1 quantitative articles addressing the validity and effectiveness of facilitated communication. Along with identifying the article and author(s), we analyzed the following details in each of the listed studies: (a) sample size; (b) subjects' characteristics, including their ages, abilities, and so forth; (c) site of the study (e.g., school, clinic); (d) duration of the study; (e) whether the facilitator and individuals being facilitated had prior experience using facilitated communication; (f) conditions and procedures of the study, including whether individuals being facilitated were provided information independent or different from the facilitators; and $(\mathrm{g})$ results and conclusions of the study.

Less rigorous studies have yielded more positive results, suggesting that facilitated communication is a functional communication tool and that individuals with severe disabilities who use facilitated communication are able to function at a level far above their estimated ability levels. Consumers of these equivocal results must decide from this conflicting information that which they believe to be most valid, or perhaps that which best fits their value or belief system.

If, indeed, facilitated communication works, it can change the way professionals view autism. Biklen (1992) proposed that individuals with autism may not have the global cognitive deficiencies accepted as commonplace among this population. He further posited that those with autism may have a condition known as global apraxia (Biklen \& Schubert, 1991; Calculator, 1992). If Biklen's position on global apraxia in individuals with autism is validated, many of the specialized educational and management techniques validated prior to the advent of facilitated communication would no longer be needed.

\section{WHAT CONSTITUTES SCIENTIFIC EVIDENCE THAT FACILITATED COMMUNICATION WORKS?}

Proponents of facilitated communication cite anecdotal reports and "qualitative" evidence (Biklen, 1993), which is purported to show the efficacy and utility of facilitated communication. Critics of facilitated communication, on the other hand, argue that evaluation of facilitated communication using traditional scientific procedures and quantitative methods have failed consistently to support independent communication abilities of individuals with serious disabilities (Simpson \& Myles, 1995; Wheeler et al., 1993). Thus, inconsistent research findings resulting from the use of different research models and methods, confront individuals attempting to analyze the efficacy of facilitated communication.

Claims that unique interventions are effective in educating and treating individuals with disabilities historically have required objective, scientific validation. Thus, claims that individuals have discovered or developed unique and efficacious curricula, procedures, or other utilitarian interventions are valid only to the extent that they are supported objectively by scientific evidence. Just as in "miracle medical treatments," many professionals consider novel educational and psychological interventions to be valid only to the extent that they are supported scientifically, especially by objective, verifiable, and reproducible observations. In this regard, the scientific method relies on a systematic, standard process that assures others that claims of effectiveness are supported by objective observations, and that nonobjective variables are either discounted or controlled (Popper, 1961). Traditional scientific methodology also relies on measurable outcomes, established research designs, empirical data-collection procedures, and quantitative data analysis (Freed, Ryan \& Hess, 1991).

Relative to education and social sciences, traditional scientific methodology has been both praised (Nagel, 1961) and faulted (Kuhn, 1970; Poplin, 1987). Notwithstanding this de- 
based on logical positivism are inept in responding to important questions, narrowly focused, and impractical (Kuhn, 1970; Voeltz \& Evans, 1983). Hanson (1958) further challenged the objectivity of logical positivism, noting that an individual's beliefs, theoretical position, and experiences influence the perception of the phenomena under consideration. These professed weaknesses, of course, are particularly significant in judging the validity and effectiveness of facilitated communication.

Contending that qualitative research procedures (e.g., methodology based on extensive naturalistic observations and detailed interviews) help researchers circumvent problems of logical positivism and traditional research methodology (Harre, 1981; Lincoln \& Guba, 1985; Taylor \& Bogdan, 1984), several professionals have used qualitative strategies to evaluate facilitated communication (Biklen, 1993; Bogdan \& Biklen, 1991; Crossley, 1992a). These researchers have relied on a variety of information sources that they argue, attest to the independent communication skills of individuals with severe disabilities who use facilitated communication, including direct observations of individuals using facilitated communication, interviews, videotapes, case studies, and analysis of observations and products written with a facilitator.

The analyses have directed attention especially to the following variables:

1. Unique typographical errors that occur consistently during use of facilitated communication.

2. Idiosyncratic spelling errors across different facilitators.

3. Use of unusual and idiosyncratic phrasing during facilitated communication.

4. Divulging information unknown to facilitators.

5. Conveying information that reveals the personality and values of the person being facilitated, which is different from that of the facilitator.

6. Communication that occurs under decreasing levels of physical contact.

Facilitated communication advocates who use qualitative research methodology contend that this alternative strategy is less intrusive and more effective than traditional procedures in assessing whether individuals with severe disabilities are able to communicate effectively with the assistance of a facilitator. Much of the purported qualitative research on facilitated communication fails to follow accepted qualitative protocol (Miles \& Huberman, 1984). What often is presented as qualitative research actually is anecdotal or case study methodology. These reports nonetheless are presented as qualitative research (Biklin, 1993; Biklin, Winston, Gold, Berrigan \& Swaminathan, 1992).

Qualitative research methodology has been criticized as unscientific, imprecise and lacking in rigor. Nevertheless, contingent upon researchers' following accepted standards and procedures, qualitative research is being accepted increasingly as a legitimate research tool (Miles \& Huberman, 1984). We acknowledge the benefits of both qualitative and traditional research, recognizing that each can be used to answer various questions. Thus, we agree with Simpson (1992) that "quantitative and qualitative procedures should be viewed as part of a research continuum, and that meaningful research should be characterized by both quantitative and qualitative aspects" (p. 236). At the same time, we agree with Simpson's (1992) assessment that, "although quantitative research methodology is far from perfect, it remains the best way to document the effectiveness of special education in a manner that provides the greatest degree of confidence in the validity and reliability of conclusions" (p. 242). We think this declaration is noteworthy, especially with regard to evaluating facilitated communication. We are of the opinion that variables associated with using and understanding facilitated communication must be controlled, and that the central question of independent authorship can be answered best using scientifically derived outcome data based on traditional research methodology.

\section{SHOULD FACILITATED COMMUNICATION BE ASSESSED QUANTITATIVELY?}

The issue of whether to assess facilitated communication quantitatively is no insignificant matter. Thus, we discuss below purported disadvantages and advantages of using traditional, objective, scientific, quantitative methods to assess facilitated communication.

One argument used to oppose objective, scientific evaluation of facilitated communication relates to purported damage to subjects' self-concepts when they participate in such investigations (Biklen, 1993). That individuals using facilitated communication must "prove themselves" and otherwise perform in an atmosphere of significant doubt as to their ability to perform is thought to undermine their already fragile selfconcepts. Because an underlying assumption of traditional scientific evidence is that a phenomenon is tested expressly for the purpose of disproving it, the existence of evaluators' doubting or dubious mindset indeed has validty. The essence of this argument is that individuals with severe disabilities have been subjected to a lifetime of experience with individuals who consider them unable to perform. Hence, exposing these individuals further to people who doubt their facilitated communication-assisted independent communication abilities subjects them to a significant performance handicap.

Opponents of robust, traditional evaluation of facilitated communication also argue that these methods introduce significant, and often unmanageable, levels of pressure and anxiety. Appealing to individuals' memories of feelings of apprehension, misgiving, and disquietude when confronted with a difficult examination, individuals opposed to scientific 
evaluation of facilitated communication suggest that, just as with nondisabled individuals, expecting people with severe disabilities to perform effectively under "examination conditions" is unreasonable.

A third argument presented in opposition of systematic and objective evaluation of facilitated communication via use of scientific methodology relates to the elimination or reduction of facilitators' high expectations. They argue that the fuel for facilitated communication is a facilitator's belief that an individual with a severe disability has the capacity for advanced thought and communication. Accordingly, they contend that objective evaluation introduces to the facilitated communication process an attitude of skepticism that contravenes or neutralizes the potential positive outcomes of the procedure.

Finally, opponents of objective, scientific evaluation of facilitated communication argue that formal evaluation introduces negative subject-related variables to settings, which interfere with communication. These variables include lack of cooperation on the part of subjects, associated with apprehension and anxiety over being evaluated. Testing situations are purported to provoke negative feelings and behaviors. Objective evaluation causes individuals who rely on facilitated communication to search for cues from their facilitators in an effort to "do well" on tests, and if these tests were not given these individuals would be relieved of these concerns and concentrate instead on communicating their thoughts and feelings. Accordingly, these variables are alleged to interfere with individuals' ability to communicate independently and functionally with others via facilitated communication.

Notwithstanding the aforementioned concerns, some individuals argue passionately that facilitated communication can and must be evaluated objectively. Those who argue for this type of evaluation contend that without scientific validation, facilitated communication will be characterized by mystique, ambiguity, and spiritual underpinnings (Calculator, 1992; Schopler, 1992). Without the support of objective validation, facilitated communication is vulnerable to allegations that it is a mysterious process that somehow is beyond reasonable human understanding and perhaps even has occult ties (e.g, Green [cited in Rimland, 1993] described the facilitated communication movement as an "insidious cult"). Indeed, some writers have noted similarities between facilitated communication and ouija boards (Calculator, 1992); and Cummins and Prior (1992) compared facilitated communication to the "Clever Hans" phenomenon, in which a horse named Hans appeared to communicate by tapping his hoof until an investigation revealed that Hans's trainer was cueing the horse. These comparisons bode poorly for widescale adoption of facilitated communication by most schools and agencies. In this regard, shedding facilitated communication's spiritual and mysterious association, it is contended, will occur only as a function of vigorous scientific investigations.
Recommendations for robust scientific validation of facilitated communication also are based on users' vulnerability to pressure to obtain positive results and severe criticism and social ostracism of individuals who fail to demonstrate the desired facilitated communication outcomes. We have experienced personally a number of incidents in which a teacher, staff member, or parent who failed to obtain the same level of communication success as others using facilitated communication was criticized severely for "not believing," "not doing it [facilitated communication] right," or otherwise being subjected to emotional blackmail for not demonstrating the same degree of success with the procedure as others.

One teacher we know related that she underwent a "gutwrenching" self-examination of her beliefs and procedures related to using facilitated communication with one of her students at home each evening for an entire semester, because she was unable to obtain the same degree of communication success as several of her colleagues and the students' parents. She went on to say that her colleagues and the students' par ents questioning of her belief in facilitated communication and her utilization of "correct methods" did little to assist her in responding to this dilemma. It seems reasonable to us that this significant problem will continue until greater understanding and objective scientific validation of facilitated communication have been achieved.

A third argument in favor of scientific, objective evaluation of facilitated communication is that the procedure has the likely potential of being used in an inconsistent and potentially wanton fashion until it is better understood. In some instances facilitators have almost no training in facilitated communication; in other cases individuals are trained to use facilitated communication with only minimal regard for specified methodology; and users of facilitated communication routinely fail to follow consistent routines and guidelines. That most colleges and universities have been reluctant to train individuals to use facilitated communication until the procedure is better understood and shown to be efficacious only intensifies this problem.

Finally, arguments in favor of scientific validation of facilitated communication are based on observations that the procedure will not be adopted widely and that it probably will not be used under optimal conditions unless it is shown objectively to be an efficacious communication method. Moreover, until facilitated communication is validated and better understood, it in all likelihood will continue be a divisive issue among staff and parents. Disagreement over use of facilitated communication can be expected to result in reluctance among many organizations and individuals to allow or sanction its use. Accordingly, individuals who do choose to use facilitated communication will likely be forced to adopt stealth strategies to conceal or camouflage their use of the method, alter use of facilitated communication in response to criticism from oth- 
ers, and otherwise fail to follow guidelines consistent with best practices of any educational tool or method.

Also, significant ethical and procedural issues are associated with evaluating facilitated communication. On the one hand, failure to evaluate facilitated communication objectively and scientifically likely will prolong the mystery of the process. In the event that facilitated communication proves to be ineffective, the delay potentially has a significant negative impact on individuals with disabilities and their families. Specifically, relying on facilitated communication when it lacks validity could (a) persuade professionals and parents to put greater emphasis on academic goals and procedures at the expense of a more functional curriculum, thus delaying development of skills and knowledge needed for independent functioning; (b) heighten frustration of people with disabilities and their families associated with incorrect decision making and reliance on inappropriate curricula and procedures; and (c) promote development of unrealistic and inaccurate expectations by parents and professionals associated with individuals with disabilities. On the other hand, robust and aggressive evaluation of facilitated communication might diminish the unknown driving force of the process, eliminating from consideration a method that may have utility with some individuals.

Moreover, scientific researchers who attempt to evaluate facilitated communication objectively need to consider and ultimately control a myriad of extraneous variables, including (a) "trust/belief" variables, (b) physical-hold variability among facilitators, (c) performance expectation variability among facilitators, (d) personality differences among faciiltators, (e) training and procedural differences among facilitators, (f) facilitator co-activity (i.e., subtle and unconscious movement of disabled individuals' hands by facilitators), and ( $\mathrm{g}$ ) skill acquisition and other performance differences among individuals with disabilities who use facilitated communication.

We are of the opinion that the aforementioned issues are extremely important and thus must be given suitable consideration. In the final analysis we see no reasonable alternatives to objective, scientific validation of facilitated communication. Accordingly, we strongly recommend continuation of the study of facilitated communication using best practices robust research methods.

We also are of the opinion that it is irresponsible for professionals who present novel intervention tools, including facilitated communication, to declare them valid independent of verifiable and independently replicable supporting data. We think it is particularly irresponsible for professionals who introduce new methods, procedures and curricula to declare that others should not attempt to evaluate or validate their claims. We believe that these declarations have the potential to undermine the very essence of development and effective use of systematic, best practices educational and treatment strategies, and thus to significantly impair advancement of the profession and the best interests of individuals with disabilities.

\section{IS THE CONFLICT SURROUNDING FACILITATED COMMUNICATION TO BE EXPECTED?}

Without question facilitated communication is a unique method, and the strident nature of the debate among professionals and parents over the use of this procedure is extreme. Perhaps more than any other new method ever conceived for assisting people with severe disabilities, facilitated communication has generated a level of interest and emotion rarely matched. In spite of these exceptional circumstances, the debate over facilitated communication is similar to discussions of other novel methods and procedures. People affected by a new method or procedure can be expected to debate its utility and use.

Adoption of new methods and procedures, particularly if the approaches challenge existing views and practices, are virtually guaranteed to provoke differences of opinion. Accordingly, disagreement over use of facilitated communication is similar to disagreements over use of other novel approaches. Moreover, innovative treatments and procedures typically are developed in natural settings such as schools and clinics rather than in research labs. As a result, new treatments, procedures, and curricula tend to be used in advance of their being validated scientifically. There is a lag between clinical application of a new treatment approach and empirical validation of that method, resulting in value-oriented and philosophical debates regarding the method. In many ways the debate over facilitated communication is typical of debates over use and adoption of other untested and innovative educational and behavioral science methods and curricula.

At the same time, some factors make the debate over facilitated communication unique. One factor is the juxtaposition of facilitated communication with the current popular trends of inclusion, integration, and empowerment of individuals with disabilities. Facilitated communication not only extends newfound hope to individuals with severe disabilities, but it also is a powerful tool to facilitate integration and inclusion. Individuals with severe disabilities who use facilitated communication not only are able to be included in normalized settings, but their integration occurs in a manner whereby they are able to function in a maximally normalized fashion. We are not suggesting that the development and proliferation of facilitated communication in this country occurred exclusively because it advances the causes of inclusion, integration, and empowerment of individuals with severe disabilities. Nonetheless, we do think these factors have supported the growth and development of facilitated communication significantly. 
A second factor that makes the debate over facilitated communication unique from discussions of other novel and newfashioned methods and procedures is its focus on individuals with autism. Autism arguably is the most complex of all disabilities, and perhaps the disability about which the most disagreement and lack of awareness exists. As demonstrated by Dustin Hoffman's portrayal of Raymond in the movie Rainman, individuals with autism sometimes have highly developed splinter skills and unique abilities along with other characteristics (e.g., normal development in select areas), which often lead others to assume they are capable of advanced functioning contingent on discovering the key to their untapped abilities. We often have heard ourselves and the families of individuals with autism with whom we work remark that a child seems capable of far more advanced functioning than he or she shows. In the eyes of some, facilitated communication offers a conduit through which they are able to reveal these purported advanced skills and abilities. Thus, facilitated communication offers a simple, convenient method for allowing individuals with autism to communicate and interact in a normalized fashion with others, actualizing the hopes, prayers, and dreams of their parents and families.

We vividly recall one mother whose son purportedly was communicating at an advanced level with facilitated communication telling us that she "always knew he could do more. He would look into my eyes and make these funny noises, and I knew he was trying to talk to me-to tell me what he was thinking and feeling. Facilitated communication gave us a way to allow our son to make contact with the world."

In the minds of many individuals, facilitated communication is a tool that serves conveniently as the key to unlocking the mystery of autism. In assuming this momentous role, debate over facilitated communication has been elevated far beyond that of other novel methods. To our knowledge, no other alternative methods or treatments have offered parents, families, and professionals of individuals with autism the hope of a simple cure.

A third explanation for why debate over use of facilitated communication is unique from other discussions, and why facilitated communication has been embraced so enthusiastically by so many families and professionals, is that it offers solutions to problems that have eluded easy, successful intervention and treatment. In spite of significant advancements made in behalf of individuals with disabilities, these persons almost always remain disabled their entire lives. Individuals with autism in particular have been inconsistently responsive to even best practices intervention methods and augmentative communication aids; and individuals with other serious developmental delays often fail to respond positively to various treatment plans. Thus it is understandable that many family members and professionals would find facilitated communication appealing. Whereas other techniques such as behavior modification and communication boards require extensive time and effort, and may yield only moderate gains, facilitated communication claims to offer individuals with severe disabilities opportunities for normal functioning, with only minimal investments of time and money.

We were impressed with the candid response of one mother of an adolescent with autism when asked why she found facilitated communication so appealing. Without hesitation she noted that ever since her child had been diagnosed with autism at age 3 , she had been given extensive advise by a "legion of doctors, psychologists, and educators - most of which did not work." She added that she did not know whether facilitated communication would work with her son, but that, "I'm damn well going to try it and see if it works; I don't have anything to lose since nothing else has worked!" This mother's remarks offer an explanation as to the unique position of facilitated communication relative to debates over novel interventions and procedures for individuals with disabilities. Facilitated communication represents hope unlike any other alternative!

The debate over facilitated communication also is unique in that it is purported to require that facilitators "believe" in the procedure. Interpretations vary as to what believe means, but the basic consensus is that individuals must have faith, trust, and an unquestioning belief in the power of facilitated communication for it to be used successfully. This required conviction on the part of users has a religious overtone and zeal that makes many potential users of facilitated communication, especially professional educators, uncomfortable. Moreover, many educators have voiced concern about a procedure that supplants the efficacy of the methodology with that of the user's belief. Not only is such an underpinning unique, but it is also virtually bound to provoke feelings and behaviors that will elevate and intensify the debate over facilitated communication beyond that of most other new procedures and conceptual models.

Finally, the debate over facilitated communication is unique with regard to the evaluation issue. The appeal of prominent advocates of facilitated communication not to evaluate the procedure by means of traditional, objective, scientific methods (Biklen, 1993; Crossley, 1992b) has provoked controversy and debate beyond what ordinarily is associated with the introduction of any novel method or procedure. We cannot recall a procedure other than facilitated communication ever having been advanced as a major intervention or problem-solving strategy with the contingency that it will be effective only if it is not evaluated. This rhetoric serves only to flame the controversy over facilitated communication, and to set this debate apart from discussions of other novel approaches that are purported to offer a new or more effective means of serving the needs of individuals with disabilities.

In summary, the debate over use of facilitated communication is following a somewhat predictable path. Innovative 
methods, especially when they radically challenge existing notions, elicit strong opinion, emotion, and debate. The facilitated communication debate, however, seems to have unique aspects that make it exceptional. In our opinion, these elements will make it difficult to easily reconcile the differences of opinion surrounding it.

\section{SHOULD FACILITATED COMMUNICATION BE USED BEFORE WE KNOW MORE ABOUT IT?}

The issue of use of facilitated communication independent of greater knowledge of the method has been debated sharply ever since facilitated communication was introduced. On the one hand, persuasive arguments exist for the use of any procedure that has the potential to assist individuals with severe disabilities to live a more independent and full life, regardless of whether traditional researchers have given their seal of approval to the method. On the other hand, convincing arguments have been presented that time and other significant resources should not be allocated to a method that has not been shown objectively to be valid, especially if doing so would require that alternative, proven procedures would have to be altered or reduced.

This dilemma is significant. Many families and professionals are requesting that facilitated communication become a regular component of childrens' educational programs, and many organizations, parents, and professionals are reluctant to commit significant resources to facilitated communication without clear evidence of its effectiveness. Although we know of few existing guidelines for helping individuals make the decision as to whether to use or not to use facilitated communication, we believe questions such as those posed by Freeman (1993) can be used as guideposts for individuals attempting to decide whether to use the procedure.

First, individuals contemplating the use of facilitated communication with an individual who has a severe disability should ask themselves whether the treatment has the potential to do harm. Just as physicians are cautioned to "first do no harm," users of facilitated communication should be prudent to engage in methods that do not impair or detract from individuals' overall educational and treatment programs. Although facilitated communication is considered in many ways to be a benign tool, it has been implicated in several false allegations of wrongdoing, such as in a number of well publicized reports of sexual abuse made by children and youth with the assistance of a facilitator.

Moreover, as with any treatment method, individual children and youth may have difficulty using facilitated communication. For instance, one child we know was moved from a special education classroom to a general education program, where he was expected to master the regular curriculum, based on his purported intellectual giftedness, discovered through his use of facilitated communication. Ultimately the child was determined to not be able to communicate independently by means of facilitated communication, and to have a significant intellectual deficit. Prior to being returned to a more appropriate curriculum, however, the youngster reportedly experienced significant frustration and regression.

Finally, individuals considering use of facilitated communication must prudently consider what a potential user must give up to use facilitated communication and whether the potential gains associated with using this method outweigh the risks. For instance, if a child's entire curriculum is altered to exclusively allow unvalidated facilitated communication, and this modification requires ongoing, effective programs such as alternative augmentative communication systems to be eliminated, significant risks to the child must be seriously considered. We agree with Freeman (1993) that the first step in considering use of facilitated communication is to determine whether it will be harmful, and to continue to pose this question during the time that facilitated communication or any other untested procedure is in use.

A second issue, pending more information about the method, is the potential impact on individuals with whom facilitated communication is used and their families if the treatment is determined to be ineffective. Parents and families of children and youth with severe disabilities frequently have referred to the "ups and downs" of living with a family member with an exceptionality (Marfo, 1988; Simpson, 1990).

One mother indicated that she and the members of her family had been "on an emotional roller coaster" ever since her daughter was diagnosed with autism. She related that she and her family had gone through a number of stages and felt a variety of emotions related to the child's disability. When she and her family were informed that her nonverbal daughter was thought to have normal intelligence and advanced social and communication abilities, based on her response to facilitated communication, the woman related how she and her family were elated and how they rejoiced in the news. But, 6 months later, when they were informed that the child's facilitated communication-assisted messages were those of a well meaning speech pathologist, she and her family were devastated. The process of dramatically adjusting their perceptions, expectations, hopes, and dreams for the child, only to learn later that these newfound beliefs were inaccurate, was an excruciating experience, and one they believed was harmful to the girl.

Of course, not every family of an individual with whom facilitated communication is used unsuccessfully will have such a strong negative reaction. Moreover, innovative and conceptually creative approaches are a key to improving services for persons with disabilities. Therefore, maintaining experimental trials using novel approaches must be continued. Nonetheless, parents and families, one must remember, are in an extremely vulnerable position. Their positive and negative emotional re- 
actions to outcomes of facilitated communication must be given careful attention.

A third issue relates to how the procedure will be integrated into a child's or youth's program. In cases in which facilitated communication is considered to be appropriate, we advise that parents and families ask themselves whether facilitated communication is balanced with other procedures and curricula. We think individuals should not become so infatuated with facilitated communication, pending greater clarity regarding the method, including its efficacy, that they lose sight of other approaches and curricula. When individuals with severe disabilities are purported to have facilitated communication-assisted normal abilities, along with unanticipated and extraordinary communication skills, we strongly recommend that existing functional curriculum, vocational, life, and social skill programs not be abandoned or neglected. We believe that individuals who have severe disabilities require functional skills even if they are responsive to using facilitated communication! Teams who assist in planning for individuals with severe disabilities are advised to ask themselves the following question: If an individual's facilitated communication-assisted performance proves to be minimal or ineffectual, will that person be potentially harmed because his or her functionally oriented program has been altered dramatically?

Another issue is whether the individual has clearly identified appropriate outcomes and assessment markers. Evaluating the use of facilitated communication, using objective assessment strategies along with ongoing informal assessment, is important. Relative to objective assessment of facilitated communication, some options circumvent purported formal evaluation problems. One method involves two basic steps:

1. After the individual with a disability has been using facilitated communication successfully, have a nonfacilitator familiar with the person discuss topics and items of interest in a setting away from the facilitator.

2. Subsequent to these discussions, have the facilitator, using facilitated communication, visit with the individual regarding what was discussed.

This procedure, which should occur several times a week subsequent to the successful implementation of facilitated communication, reduces the purported problems of formal testing (e.g., challenging an individual's ability) by creating an informal atmosphere in which to exchange and discuss information. At the same time, this method allows users of facilitated communication to evaluate its utility and thus to make objective decisions regarding the extent to which an individual with a disability is able to communicate using the method independently.

Informal assessment of facilitated communication involves monitoring a variety of outcomes related to the use of facilitated communication. For instance, is the facilitator able to fade physical contact as the individual becomes more experienced in using facilitated communication? Does the individual using facilitated communication demonstrate behavioral and social interaction changes (especially improvements) during and after use of the procedure? Does the individual give evidence of wanting to use facilitated communication independently? Is the individual able to use facilitated communication effectively with more than one facilitator? Is the individual able to use independently the communication mode used in facilitated communication (e.g., Canon Communicator, alphabet board) to complete basic academic tasks (e.g., write name, address, phone number; identify letters of the alphabet)? Of course, the factors that are monitored will vary from individual to individual. The important point in this process is to select meaningful outcomes associated with facilitated communication, including those identified on students' IEPs, and consistently monitor them.

In summary, responsible parents and professionals should be free to choose whether they do or do not want to use facilitated communication, independent of its being understood more clearly and prior to the final scientific verdict on its validity being rendered. This advice is provided with cautions, though. Not only does facilitated communication lack scientific validity, but its use also has the potential to do harm. Nonetheless, some individuals with disabilities may respond positively to facilitated communication. They may be able to use facilitated communication to communicate even if they fail to demonstrate the extraordinary outcomes that have been advertised so prominently (Biklen, 1993). In our opinion, individuals who choose to try facilitated communication should do so with great prudence, including use of a well designed evaluation plan.

\section{WHAT LIFE-SPAN ISSUES SHOULD BE ADDRESSED FOR PERSONS WHO USE FACILITATED COMMUNICATION?}

Regardless of whether facilitated communication is or is not a revolutionary breakthrough of grave import to individuals with disabilities, as some have suggested (Biklen, 1993), or simply an additional augmentative communication alternative for some individuals, its long term use has significant implications. Individuals with whom facilitated communication is used, along with families and professionals who recommend and support its use, must contend with a number of significant issues associated with post-school preparation and life span success.

One set of issues relates to the resources needed to hire, train, and maintain one-to-one facilitators for children, youth, and adults with severe disabilities; whether human and nonhuman facilitated communication resources are available over 
the long term; and whether facilitated communication effectively promotes long-term goals for individuals with severe disabilities. Legislative enactments clearly have supported the need for appropriate resources and related services for children and youth with disabilities, and adults with disabilities also have access to a variety of options for needed services. Thus, clear mandates are in place for services that individuals with disabilities need to function in normalized settings to the maximum extent possible.

Nonetheless, parents and professionals who recommend use of facilitated communication must not lose sight of whether facilitated communication promotes independent functioning in a cost-efficient fashion over a lifetime, and whether one-to-one facilitators will always be available, and if so, whether their availability will facilitate the person's independent functioning. If interventions and strategies for a youth or young adult with a disability are to promote independent living and to assist an individual to become an independent or semi-independent worker in a supported system, stakeholders must consider objectively whether relying exclusively on facilitated communication has utility and cost-efficiency.

Careful consideration of this issue is important particularly in cases in which individuals who require one-to-one facilitators are unable to use facilitated communication independently after extensive training, and when the long-term availability of resources needed to support facilitated communication is in doubt. Simply stated, if an individual is unable to use independently and effectively a communication system, including facilitated communication, after a reasonable period of training and use, we seriously question whether that alternative truly promotes the individual's long term growth and development.

A second life-span consideration associated with facilitated communication relates to alternatives for curricula and educational objectives. Designed to be an alternative communication mode, facilitated communication purportedly allows individuals with severe disabilities to interact with others in a "normal" fashion. Related to this performance, parents and professionals who use facilitated communication with individuals with severe disabilities - especially when these individuals reveal extraordinary or highly advanced skills and knowledge that are incongruent with prior assessment and performance-must decide whether an individual should (a) be allowed or encouraged to pursue an advanced, age-appropriate general education curriculum, (b) continue with a functional curriculum (e.g., self help and independent living skills), or (c) be exposed to a combination of these program alternatives. In many respects, this issue is at the heart of the debate over use of facilitated communication. If facilitated communication permits individuals with severe disabilities to communicate and interact with others in an ageappropriate fashion, they logically should be permitted and encouraged to pursue educational and training programs that facilitate their developing skills and obtaining knowledge compatible with their true abilities. On the other hand, if individuals with severe disabilities are encouraged to pursue an advanced curriculum based on their facilitated communication performance and it is determined later that the person was not the independent author of the products written using facilitated communication, the individual may have been placed in a frustrating position and would have made better use of educational opportunities by pursuing a more functional curriculum. Because these issues are so deeply steeped in emotion and personal values, easy and simple answers will not likely be forthcoming.

The significance of this issue is illustrated by an observation we made recently of a youth with autism. This nonverbal fifteen-year-old was assessed to have severe mental retardation and behavior problems so serious as to require extensive support services. When exposed to facilitated communication, however, the young man purportedly communicated that he was not "retarded," and that he wanted to be reassigned from his special education classroom to general education. His request, supported by his jubilant parents, was honored. With the support of a fulltime facilitator, he was enrolled in general education classes, including a math class for gifted students. On the occasion we observed the youth, he was in a science class working with his facilitator on identifying parts of the brain. Later we observed the youth in a math class for gifted students, where, with the assistance of his facilitator, he was able to answer correctly a variety of advanced algebra questions. At lunchtime the youth was assisted in going through the cafeteria line by a special education paraprofessional, who stood next to the student and pushed his lunch tray along a railing, placing various food items on the tray. During the time the paraprofessional was gathering the youth's lunch (he had no choices of food), he vigorously engaged in self-stimulatory behavior, flapping his lunch ticket in one hand and a comb in the other. The youth and the paraprofessional reached the woman who was gathering lunch tickets, who asked him for his ticket. Ignoring the lunch attendant, the youth continued to wave the ticket and comb until the paraprofessional prompted him verbally and physically to put his hands down, followed by a verbal prompt to "give her your lunch ticket." After several seconds the youth extended his hand with the comb. The paraprofessional then physically prompted the student to extend the hand containing the lunch ticket, whereupon the student compliantly yielded his ticket to the lunch attendant.

We found the lack of congruence between this student's facilitated communication enhanced academic performance and his lunchroom performance significant. With facilitated communication the youth was able to complete advanced science and math lessons and activities successfully. In the lunch room, however, he was unable to discriminate between his lunch ticket and comb. We found ourselves wondering if the 
curriculum to which this youth was exposed truly supported his developing the skills that he likely will need to live and work independently and productively. This scenario graphically illustrates the curriculum and program choice dilemma faced by individuals who respond successfully to facilitated communication and the consequences of these choices.

A third lifespan issue concerns the impact of facilitated communication on general quality of life of individuals with disabilities. Does facilitated communication improve the social behavior and social interaction skills of individuals with disabilities, assist them in finding appropriate employment and living options, create additional leisure and recreational alternatives, enhance their overall happiness and satisfaction and the happiness of their families, and so forth? Although evaluation of these factors is anything but simple, we nonetheless think that those who use or plan to use facilitated communication should attempt to gauge its potential impact on variables fundamental to enjoyment and satisfaction over the life span.

\section{WHAT ISSUES SHOULD BE ADDRESSED WHEN STUDYING FACILITATED COMMUNICATION?}

As we have stated repeatedly, vigorous scientific research of facilitated communication should be undertaken. The initial efforts should be continued and expanded. We recommend specifically that the following three major research themes be pursued in an attempt to understand facilitated communication better: (a) research of the technique itself, (b) research focusing on co-activity as an element of facilitated communication, and (c) research on potential instructional uses of facilitated communication.

Investigation of the facilitated communication technique relates to learning more about the procedure. In this regard, the following basic questions should be addressed:

1. First and foremost, is facilitated communication an effective communication tool, and do individuals who use facilitated communication have independent capacity for performance significantly above their estimated level of ability?

2. Is facilitated communication more effective than other communication methods, and, if so, with whom is the method most apt to be effective?

3. How and why does facilitated communication work? What are the mechanics and elements of effective facilitated communication programs?

4. How does facilitated communication performance differ for tasks in which facilitators know and do not know the answers to questions?

5. What is the relationship between oral and written language and motor impairment for individuals who do and do not respond positively to facilitated communication?
A myriad of additional questions related to facilitated communication could be posed. We are of the opinion, however, that addressing these issues is basic to better understanding the facilitated communication technique.

Co-activity research relates to better understanding the relationship between individuals with disabilities who are assisted in communicating by means of facilitated communication and the individuals who facilitate them. This relationship is poorly understood and also is the primary source of controversy over facilitated communication. Specific questions related to facilitated communication co-activity that we think deserve serious consideration include the following:

1. How aware are facilitators that they are or may be influencing facilitated communication-assisted written language?

2. How can facilitated communication co-activity be controlled, and what is the impact of this control on individuals' ability to communicate?

3. What role does the interpersonal relationship and rapport between facilitators and individuals with disabilities play for individuals who use facilitated communication successfully and unsuccessfully?

4. What factors contribute to successful facilitated communication relationships?

5. What technical and interpersonal skills do facilitators need to help individuals with disabilities use facilitated communication successfully?

6. Are mechanical or other nonhuman facilitated communication supports available that may be supplanted for facilitators?

7. What are the steps and procedures for fading or reducing facilitated communication support successfully?

Facilitated communication disputes largely have centered on issues of independent authorship. Thus, research leading to better understanding of the co-activity and relationship between facilitators and those they facilitate is essential.

Finally, researchers interested in facilitated communication should consider the instructional role of the process. If individuals with severe disabilities can express their thoughts and feelings using facilitated communication, educators and other professionals should be able to use this tool more effectively for teaching and training. Facilitated communication thus far has been limited to use as a method for permitting individuals with disabilities to impart information, rather than also using the procedure to input knowledge and skills. Accordingly, dyads who use facilitated communication successfully should be studied to determine methods of allowing facilitators to instruct and interact with individuals with whom they are involved, rather than using this tool simply for one-way communication. 


\section{SUMMARY THOUGHTS}

Support for facilitated communication has come in the form of informal reports and case studies, including idiosyncratic spellings and phrasings of individuals with disabilities with different facilitators, unique typographical errors of individuals being facilitated, typing information that reveals an individual's peculiarities and unique characteristics, and people with severe disabilities divulging information purportedly unknown to facilitators. In defense of this form of support for the validity of facilitated communication, Crossley (1988; 1992b) and Biklen and Schubert (1992) have claimed that systematic attempts to validate scientifically facilitated communication would violate the trust bond between communicator and facilitator by suggesting that the individual with a disability was unable to communicate independently or otherwise was incompetent. Because of this concern, Biklen and Schubert (1991) have recommended that objective, scientific validation of facilitated communication not be undertaken.

In spite of these considerations, a number of researchers have used robust and objective scientific procedures to study facilitated communication. This research has been designed to identify objectively authors of facilitated communicationassisted products by posing questions to which the facilitators did not know the answers (Myles \& Simpson, 1994; Simpson \& Myles, 1995; Wheeler et al., 1993). As shown in Table 1, these scientific validation studies have concluded consistently that when facilitators lacked information needed to answer questions asked of the individuals being facilitated, the latter were unable to communicate independently.

This dramatic disagreement of research methods and findings has been at the core of the facilitated communication controversy. Moreover, facilitated communication has engendered a political and value-oriented debate. That is, in spite of consistent objective research results finding that individuals with severe disabilities cannot demonstrate cognitive, social, and communication abilities that transcend their current estimated or calculated functioning level significantly, facilitated communication has come to represent a means by which individuals with disabilities are able to be integrated fully as members of "normal" society. Accordingly, many parents and professionals who advocate for full rights for individuals with severe disabilities perceive facilitated communication as their best hope for the future. That equally effective traditional treatments and interventions for individuals with severe disabilities are unavailable, and that research results support both the validity and the invalidity of facilitated communication, has served to fuel and perpetuate this controversy.

The strident debate over facilitated communication has left many professionals, parents, and families searching for a "bottom-line" answer to the question, "Is facilitated communication a functional and legitimate tool that should be used with children, youth, and adults with severe disabilities?" A simple answer that will satisfy all stakeholders is not likely to be accepted any time soon. Rather, opinions, inferences, and individual perspectives most likely will continue to be the means by which facilitated communication is judged. In this regard, we believe that facilitated communication must be judged on its outcomes-whether it can or cannot be shown objectively and scientifically to assist persons with disabilities to communicate effectively and function independently in an ever more complex world. In our opinion, interventions for people with disabilities, including facilitated communication, should bring about scientifically valid improvements in language, social, cognitive, motor, vocational, self-help, and independent living functioning.

We are convinced that facilitated communication is not a miraculous phenomenon or a cure for disabilities. Nonetheless, it may be a potentially useful communication tool for some individuals with disabilities. Accordingly, we urge professionals and parents to continue their quest to validate objectively the scientific merits of facilitated communication and to identify its legitimate educational and habilitative uses. Only through this process will objective information be made available to guide professionals, parents, families, and others in making responsible choices regarding facilitated communication, including the extent to which resources should be committed to using this unique procedure.

\section{REFERENCES}

Autism Society of America. (1992-93, Winter). Facilitated communication under the microscope. Advocate, 19-20.

Biklen, D. (1990). Communication unbound: Autism and praxis. Harvard Educational Review, 60(3), 291-314.

Biklen, D. (1992). Typing to talk: Facilitated communication. American Journal of Speech and Language Pathology, 1(2), 15-17.

Biklen, D. (1993). Communication unbound: How facilitated communication is challenging traditional views of autism and ability/disability. New York: Teachers College Press.

Biklen, D., \& Schubert, A. (1991). New words: The communication of students with autism. Remedial \& Special Education, 12(6), 46-57.

Biklen, D., \& Schubert, A. (1992). Communication unbound: The story of facilitated communication. Paper presented at 1992 national symposium, Current Issues in the Nature and Treatment of Autism. St. Louis: Missouri Department of Mental Health Conference.

Biklin, D., Winston, M., Gold, D., Berrigan, C., \& Swaminathan, S. (1992). Facilitated communication: Implications for individuals with autism. Topics in Language Disorders, 12(4), 1-28.

Bligh, S., \& Kupperman, P. (1993). Brief report: Facilitated communication evaluation procedure accepted in a court case. Journal of Autism \& Developmental Disorders, 23(3), 553-557.

Bogdan, R., \& Biklen, S. (1991). Qualitative research for education: An introduction to theory and methods. Boston: Allyn \& Bacon. 
Calculator, S. N. (1992). Perhaps the emperor has clothes after all: A response to Biklen. American Journal of Speech and Language Pathology, 1(2), 18-20.

Calculator, S., \& Singer, K. (1992). Letter to the editor: Preliminary validation of facilitated communication. Topics in Language Disorders, 13, ix-xvi.

Crossley, R. (1988, October). Unexpected communication attainments by persons diagnosed as autistic and intellectually impaired. Unpublished paper presented at International Society for Augmentative and Alternative Communication, Los Angeles, CA.

Crossley, R. (1992a). Communication training involving facilitated communication. In DEAL Communication Centre (Eds.), $\mathrm{Fa}$ cilitated communication training (pp. 1-9). Melbourne, Australia: DEAL Communication Centre.

Crossley, R. (1992b). Who said that? In DEAL Communication Centre (Eds.), Facilitated communication training (pp. 42-54). Melbourne, Australia: DEAL Communication Centre.

Cummins, R., \& Prior, M. (1992). Autism and assisted communication: A response to Biklen. Harvard Educational Review, 62(2), 228-241.

Eberlin, M., McConnachie, G., Ibel, S., \& Volpe, L. (1993). Facilitated communication: A failure to replicate the phenonmenon. Journal of Autism \& Developmental Disorders, 23(3), 507-530.

Feigl, H., \& Brodbeck, M. (1953). Readings in the philosophy of science. New York: Appleton Century Crofts.

Freed, M. N., Ryan, J. M., \& Hess, R. K. (1991). Handbook of statistical procedures and their computer applications to education and the behavioral sciences. New York: Macmillan.

Freeman, B. J. (1993). Questions to ask regarding specific treatment. Advocate, 25(2), 19.

Hanson, N. R. (1958). Patterns of discovery: An inquiry into the conceptual foundations of science. Cambridge, England: Cambridge University Press.

Harre, R. (1981). The positivist-empiricist approach and its alternative. In P. Reason \& J. Rowan (Eds.), Human inquiry: A sourcebook of new paradigm research (pp. 116-137). New York: Wiley.

Hudson, A., Melita, B., \& Arnold, N. (1993). Brief report: A case study assessing the validity of facilitated communication. Journal of Autism \& Developmental Disorders, 23(1), 165-173.

Intellectual Disability Review Panel. (1989). Investigation into the reliability and validity of the assisted communication technique. Melbourne, Victoria: Department of Community Services.

Kerlinger, F. N. (1986). Foundations of behavioral research (3rd ed.). New York: Holt, Rinehart \& Winston.

Klewe, L. (1993). Brief report: An empirical evaluation of spelling boards as a means of communication for the multihandicapped. Journal of Autism \& Developmental Disorders, 23(3), 559-566.

Kuhn, T. S. (1970). The structure of scientific revolutions (2nd ed.). Chicago: University of Chicago Press.

Lincoln, Y. S., \& Guba, E. G. (1985). Naturalistic inquiry. Beverly Hills: Sage.

Marfo, K. (Ed.). (1988). Parent-child interaction and developmental disabilities. New York: Praeger.

Miles, M. B., \& Huberman, A. M. (1984). Qualitative data analysis. Newbury Park, CA: Sage.
Mulick, J. A., Jacobson, J. W., \& Kobe, F. H. (1993). Anguished silence and helping hands: Autism and facilitated communication. Skeptical Inquirer, 17(3), 270-280.

Moore, S., Donovan, B., \& Hudson, A. (1993). Brief report: Facilitatorsuggested conversational evaluation of facilitated communication. Journal of Autism \& Developmental Disorders, 23(3), 541-552.

Moore, S., Donovan, B., Hudson, A., Dykstra, J., \& Lawrence, J. (1993). Brief report: Evaluation of eight case studies of facilitated communication. Journal of Autism \& Developmental Disorders, 23(3), 531-539.

Myles, B. S., \& Simpson, R. L. (1994). Facilitated communication with children diagnosed as autistics in public school settings. Psychology in the Schools, 31, 208-220.

Nagel, E. (1961). The structure of science. New York: Harcourt, Brace and World.

Ogletree, B. T., Hamtil, A., Solberg, L., \& Scoby-Schmelzle, S. (1993). Facilitated communication: Illustration of a naturalistic validation method. Focus on Autistic Behavior, 8(4), 1-13.

Poplin, M. (1987). Self-imposed blindness: The scientific method in education. Remedial \& Special Education, 8(6), 31-37.

Popper, K. R. (1961). The logic of scientific discovery. London: Hutchinson.

Prior, M., \& Cummins, R. (1992). Questions about facilitated communication. Journal of Autism \& Developmental Disorders, 22(3), 331-338.

Regal, R. A., Rooney, J. R., \& Wandas, T. (1994). Facilitated communication: An experimental evaluation. Journal of Autism \& Developmental Disorders, 24(3), 345-355.

Rimland, B. (1992a). A facilitated communication "horror story." Autism Research Review, 6(1), 1, 7.

Rimland, B. (1992b). Facilitated communication: Problems, puzzles and paradoxes: Six challenges for researchers. Autism Research Review, 5(4), 3.

Rimland, B. (1993). Facilitated communication under siege. Autism Research Review International, 7(1), 2, 7.

Schopler, E. (1992). Facilitated communication-hope or hype? Autism Society of North Carolina, 8(3), 6.

Simpson, R. (1992). Quantitative research as the method of choice within a continuum model. In Stainback \& Stainback (Eds.), Controversial issues confronting special education: Divergent perspectives (pp. 235-251). Boston: Allyn \& Bacon.

Simpson, R. L. (1990). Conferencing parents of exceptional children. Austin, TX: PRO-ED.

Simpson, R. L. (1993). Facilitated communication. Director, 8(2), 6-7.

Simpson, R. L., \& Myles, B. S. (1995). Effectiveness of facilitated communication with children and youth with autism. Journal of Special Education, 28(4), 424-439.

Smith, M. D., \& Belcher, R. G. (1993). Brief report: Facilitated communication with adults with autism. Journal of Autism \& Developmental Disorders, 23(1), 175-183.

Szempruch, J., \& Jacobson, J. W. (1993). Evaluating facilitated communication of people with developmental disabilities. Research in Developmental Disabilities, 14, 253-264.

Taylor, S., \& Bogdan, R. (1984). Introduction to qualitative research methods. New York: John Wiley. 
Vasquez, C. A. (1994). Brief report: A multitask controlled evaluation of facilitated communication. Journal of Autism \& Developmental Disorders, 24,(3), 369-379.

Voeltz, L. M., \& Evans, I. M. (1983). Educational validity: Procedures to validate outcomes in programs for severely handicapped learners. Journal of the Association for the Severely Handicapped, 6, 3-15.

Wheeler, D., Jacobson, J., Paglieri, R., \& Schwartz, A. (1993). An experimental assessment of facilitated communication. Mental Retardation, 31, 49-60.
The research reported here was supported by Grant No. H023A20093 from the U.S. Department of Education, Office of Special Education Research, Division of Innovation and Development. Points of view or opinions stated in this article do not necessarily represent official agency positions.

INDEX • Volume 27

Author Index

Brengelman, Susan (September 1994)

Carta, Judith J. (April 1995)

Colson, Steven (December 1994)

Gersten, Russell (September 1994)

Jiménez, Robert (September 1994)

Kleinhammer-Tramill, Jeannie P. (October 1994)

Myles, Brenda Smith (May 1995)

Nelson, C. Michael (February 1995)

Nolet, Victor (November 1994 \& March 1995)

Rivera, Diane Pedrotty (January 1995)

Rosenkoetter, Sharon E. (October 1994)

Rutherford, Robert B. (February 1995)

Simpson, Richard L. (May 1995)

Smith, Deborah Deutsch (January 1995)

Tindal, Gerald (November 1994 \& March 1995)

Tramill, James L. (October 1994)

Tyler, Janet Siantz (December 1994)

\section{Chronological Index of Titles}

Effective Instruction for Culturally and Linguistically Diverse Students: A Reconceptualization (September 1994)

Early Intervention and Secondary/Transition Services: Harbingers of Change in Education (October 1994)

Curriculum-Based Collaboration (November 1994)

Common Pediatric Disabilities: Medical Aspects and Educational Implications (December 1994)

Discipline in Special Education and General Education Settings (January 1995)

Management of Aggressive and Violent Behavior in the Schools (February 1995)

Curriculum-Based Measurement in Middle and High Schools: Critical thinking Skills in Content Areas (March 1995)

Developmentally Appropriate Practice: A Critical Analysis as Applied to Young Children with Disabilities (April 1995)

Facilitated Communication and Children with Disabilities: An Enigma in Search of a Perspective (May 1995) 